\title{
Role of matrix metalloproteinases in the development of airway inflammation and remodeling
}

V. Lagente, B. Manoury, S. Nénan, C. Le Quément,

C. Martin-Chouly and $\mathrm{E}$. Boichot
INSERM U620, Faculté de Pharmacie, Université de Rennes 1, Rennes, France

\author{
Correspondence \\ V. Lagente \\ INSERM U620 \\ Université de Rennes I \\ 2, Avenue du Pr. Léon Bernard \\ 35043 Rennes Cedex \\ France \\ Fax: $+33-2-2323-4794$ \\ E-mail: \\ vincent.lagente@univ-rennes1.fr \\ Presented at SIMEC 2004 \\ (International Symposium \\ on Extracellular Matrix), \\ Angra dos Reis, RJ, Brazil, \\ September 27-30, 2004. \\ Research supported by a grant from \\ Conseil Régional de Bretagne \\ (ref. \#2004797) and by a \\ collaborative project between INSERM \\ (France) and FIOCRUZ (Brazil).
}

Received February 16, 2005

Accepted May 20, 2005

\begin{abstract}
Matrix metalloproteinases (MMPs) are a major group of proteases known to regulate extracellular matrix (ECM) turnover and so they have been suggested to be important in the process of lung disease associated with tissue remodeling. This has led to the concept that modulation of airway remodeling including excessive proteolysis damage to the tissue may be of interest for future treatment. Within the MMP family, macrophage elastase (MMP-12) is able to degrade ECM components such as elastin and is involved in tissue remodeling processes in chronic obstructive pulmonary disease including emphysema. Pulmonary fibrosis has an aggressive course and is usually fatal within an average of 3 to 6 years after the onset of symptoms. Pulmonary fibrosis is associated with deposition of ECM components in the lung interstitium. The excessive airway remodeling as a result of an imbalance in the equilibrium of the normal processes of synthesis and degradation of ECM components could justify anti-protease treatments. Indeed, the correlation of the differences in hydroxyproline levels in the lungs of bleomycin-treated mice strongly suggests that a reduced molar pro-MMP-9/TIMP-1 ratio in bronchoalveolar lavage fluid is associated with collagen deposition, beginning as early as the inflammatory events at day 1 after bleomycin administration. Finally, these observations emphasize that effective treatment of these disorders must be started early during the natural history of the disease, prior to the development of extensive lung destruction and fibrosis.
\end{abstract}

Key words

- Fibrosis

- Inflammation

- Lung

- Matrix metalloproteinase

- Tissue inhibitor of matrix metalloproteinases

- Chronic obstructive pulmonary disease

\section{Introduction}

Matrix metalloproteinases (MMPs), also called matrixins, are zinc-dependent endopeptidases, known for their ability to cleave one or several constituents of the extracellular matrix (ECM). They contain a large family of proteases that share common structural and functional elements and are produced by different genes. These enzymes are primarily distinguished from other classes of proteinases by their dependence on metal ions and neutral $\mathrm{pH}$ for activity. Zymogen forms of the MMPs (pro-MMPs) are secreted into the matrix from a large number of cell types and activation of the pro-MMPs in the local microenvironment can result in discrete alterations in tissue architecture. 


\section{Matrix metalloproteinase family}

Depending on substrate specificity, amino acid similarity and identifiable sequence modules, the MMP family can be classified into distinct subclasses: collagenases (MMP$1,-8,-13$ ), gelatinases (MMP-2, -9), stromelysins (MMP-3, -10, -11), membrane-type MMP (MMP-14 to MMP-25), matrilysin (MMP-7), and macrophage metalloelastase (MMP-12; Table 1) (1). Comparative sequence analysis of the MMPs has revealed the molecular characteristics of these proteins: i) signal sequence, to direct secretion from the cell, ii) N-terminal pro-domain (propeptide), involved in maintaining the latency of proteins, including a highly conserved sequence PRCGVPDV, iii) catalytic domain, including the consensus HexxHxx GxxH zinc-binding motif, iv) C-terminal domain (hemopexin-like domain), implicated in macromolecular substrate recognition, and v) a cysteine residue in the pro-peptide of the enzyme (pRCGVPDV sequence) that maintains the latency of the zymogen by direct coordination with the active site zinc atom of the catalytic domain, blocking the access of the catalytic site to the substrate. Interruption of this interaction by aminophenyl mercuric acetate, $\mathrm{HgCl}_{2}, \mathrm{HOCl}$, oxidized glutathione, by heat treatment, or by other proteases, including MMPs, initiates a cascade of events that alters the conformation of the protein. Following opening of the cysteine$\mathrm{Zn}$ bond, a series of auto-catalytic cleavages result in excision of the remainder of the pro-peptide to yield a proteolytically truncated and catalytically competent enzyme (1).

The major physiologic inhibitors of the MMPs in vivo are $\alpha-2$ macroglobulin and the family of specific tissue inhibitor of MMPs (TIMPs), naturally occurring proteins specifically inhibiting these proteases and produced by many cell types. The TIMP family at present comprises four structurally related members, TIMP-1, -2 , and -3 , and the recently discovered TIMP-4. They have relative molecular masses ranging from 22 to $30 \mathrm{kDa}$, with $40-50 \%$ sequence identity. Of these, TIMP-1 and -2 are secreted in soluble form, whereas TIMP-3 is associated with the ECM. The TIMPs bind with high affinity in a 1:1 molar ratio to the catalytic site of active MMPs, resulting in loss of proteolytic activity. Moreover, TIMP-1 and TIMP-2 can form a specific complex with pro-MMP-9 and pro-MMP-2, respectively. This interaction has been suggested to provide an extra level of regulation by potentially preventing activation. However, it has recently been shown that TIMP-2 forms a tri-molecular complex on the surface of the cell with MT1-MMP and pro-MMP-2. This ternary complex is critical for the activation of pro-MMP-2 (2).

\section{Role of MMP in the development of airway inflammation in chronic obstructive pulmonary disease}

Chronic obstructive pulmonary disease (COPD) is one of the major causes of mortality and morbidity all over the world and its prevalence is still increasing (3). The major triggering factor is cigarette smoking, which accounts for $80-90 \%$ of the COPD cases. However, in the population of smokers, only $15 \%$ of the subjects develop chronic airflow limitation (4).

COPD is characterized by the presence of a partially reversible airflow obstruction. This pathology is also associated with an airway inflammatory process characterized by an accumulation of inflammatory cells such as macrophages and neutrophils. Indeed, it has been shown that cigarette smoke consistently produces an increase in neutrophil numbers in bronchoalveolar lavage (BAL) fluid and in tissue $(5,6)$. Macrophage numbers are also elevated in the lungs of smokers and of patients with COPD where they accumulate in the alveoli, bronchioli and small airways. Furthermore, there is a 
Table 1. The family of matrix metalloproteinases and tissue inhibitors of metalloproteinases.

\begin{tabular}{|c|c|c|c|c|c|}
\hline \multirow[t]{2}{*}{ Subgroup } & \multirow[t]{2}{*}{ MMP } & \multirow[t]{2}{*}{ Enzyme } & \multicolumn{2}{|c|}{ Molecular mass (kDa) } & \multirow[t]{2}{*}{ Known substrate(s) } \\
\hline & & & Latent & Active & \\
\hline \multirow[t]{6}{*}{ Collagenases } & MMP-1 & Interstitial collagenase-1 & 55 & 45 & $\begin{array}{l}\text { Collagens I, II, III, VII, VIII; gelatin; aggrecan; versican; } \\
\text { proteoglycan link protein; casein; } \alpha \text {-proteinase inhibitor; } \\
\alpha \text {-macroglobulin; ovostatin; nidogen; pro-TNF; L-selectin; } \\
\text { MMP-2; MMP-9 }\end{array}$ \\
\hline & MMP-18 & $\begin{array}{l}\text { Interstitial collagenase- } 4 \\
\text { (Xenopus) }\end{array}$ & 53 & $?$ & \\
\hline & MMP-8 & Neutrophil collagenase & 75 & 58 & Collagens I, II, III, V, VII, VIII, X; gelatin; aggrecan; $\alpha$-proteinase \\
\hline & MMP-13 & Collagenase-3 & 60 & 48 & inhibitor; fibronectin \\
\hline & MMP-15 & Xenopus collagenase & 55 & $?$ & Collagens I, II, III, IV; gelatin; aggrecan; perlecan; tenascin \\
\hline & MMP-21 & Collagenase-4 & 72 & $?$ & (see MMP-24) \\
\hline \multirow[t]{4}{*}{ Stromelysins } & MMP-3 & Stromelysin-1 & 57 & 45 & $\begin{array}{l}\text { Collagens III, IV, IX, X; gelatin; aggrecan; versican; perlecan; } \\
\text { fibronectin; laminin; elastin; casein; fibrinogen, } \alpha \text {-macroglobulin; } \\
\text { ovostatin; pro-TNF; MMP-1, 7, 8, 9, } 13\end{array}$ \\
\hline & MMP-10 & Stromelysin-2 & 57 & 44 & $\begin{array}{l}\text { Collagens III, IV, V; gelatin; casein; aggrecan; elastin; fibronectin; } \\
\text { MMP-1, 8; } \alpha \text {-proteinase inhibitor }\end{array}$ \\
\hline & MMP-19 & $\begin{array}{l}\text { RASI or MMP-18 } \\
\text { (human) }\end{array}$ & 57 & ? & Aggrecan and cartilage oligomeric matrix protein; amelogenin \\
\hline & MMP-20 & Enamelysin & 54 & $?$ & Amelogenin; enamel matrix; aggrecan \\
\hline \multirow[t]{2}{*}{ Gelatinases } & MMP-2 & Gelatinase A & 72 & 66 & $\begin{array}{l}\text { Collagens I, IV, V, VII, X, XI, XIV; gelatin; elastin; } \\
\text { fibronectin; aggrecan; perlecan; versican; ß-amyloid; } \\
\text { pro-TNF; } \alpha \text {-proteinase inhibitor; MMP-9, } 13\end{array}$ \\
\hline & MMP-9 & Gelatinase B & 92 & 86 & $\begin{array}{l}\text { Collagens IV, V, VII, X, XIV; gelatin; elastin; aggrecan; versican; } \\
\text { fibronectin; nidogen; } \alpha \text {-proteinase inhibitor; pro-TNF }\end{array}$ \\
\hline \multirow[t]{3}{*}{ Elastases } & MMP-7 & Matrilysin (PUMP-1) & 28 & 19 & $\begin{array}{l}\text { Collagens I, II, III; gelatin; aggrecan; fibronectin; laminin; entactin; } \\
\text { elastin; casein; transferring; } \alpha \text {-proteinase inhibitor; pro-TNF; } \\
\text { MMP-1, } 2,9\end{array}$ \\
\hline & MMP-26 & $\begin{array}{l}\text { Matrilysin-2 or } \\
\text { endometase }\end{array}$ & 30 & $?$ & $\begin{array}{l}\text { Collagen type IV; fibronectin; fibrinogen; beta-casein; type I } \\
\text { gelatin; } \alpha-1 \text { proteinase inhibitor. Is also able to activate } \\
\text { pro-gelatinase B }\end{array}$ \\
\hline & MMP-12 & $\begin{array}{l}\text { Macrophage } \\
\text { metallo-elastase }\end{array}$ & 54 & $45 / 22$ & $\begin{array}{l}\text { Collagen IV; gelatin; elastin; } \alpha \text {-proteinase inhibitor; } \\
\text { fibronectin; vitronectin; laminin; pro-TNF }\end{array}$ \\
\hline cAMP metalloproteinase & MMP-23 & & 44 & $?$ & $?$ \\
\hline$?$ & MMP-28 & Epilysin & 59 & $?$ & Casein \\
\hline \multirow[t]{6}{*}{ Membrane type MMPs } & MMP-14 & MT1-MMP & 66 & 56 & $\begin{array}{l}\text { Collagens I, II, III; gelatin; casein; elastin; fibronectin; laminin B } \\
\text { chain; vitronectin; aggrecan; dermatan sulfate proteoglycan; } \\
\text { MMP-2, 13; pro-TNF }\end{array}$ \\
\hline & MMP-15 & MT2-MMP & 72 & $?$ & \\
\hline & MMP-16 & MT3-MMP & 64 & 52 & MMP-2; gelatin; fibronectin; tenascin; nidogen; laminin \\
\hline & MMP-17 & MT4-MMP & 67 & $?$ & MMP-2 \\
\hline & MMP-24 & $\begin{array}{l}\text { MT5-MMP or } \\
\text { MMP-21 }\end{array}$ & 70 & $?$ & $\begin{array}{l}\text { Fibrin; pro-TNF; activation of pro-gelatinase A. Does } \\
\text { not hydrolyze collagen types I, II, III, IV, and V, gelatin, } \\
\text { fibronectin, laminin, decorin nor } \alpha 1 \text {-antitrypsin }\end{array}$ \\
\hline & MMP-25 & $\begin{array}{l}\text { MT-MMP-6 or } \\
\text { leukolysin }\end{array}$ & 63 & $?$ & $\begin{array}{l}\text { Specifically activates pro-gelatinase A and proteoglycans, such } \\
\text { as dermatan sulfate and chondroitin sulfate proteoglycans. } \\
\text { Cleaves partially fibronectin, but not collagen type I, nor laminin. } \\
\text { Activation of pro-gelatinase A }\end{array}$ \\
\hline \multirow[t]{4}{*}{ Tissue inhibitor of MMPs } & TIMP-1 & & \multicolumn{2}{|c|}{28.5 (glycosylated } & All MMPs except MMP-14, MMP-19. Binds to pro-MMP-9 \\
\hline & TIMP-2 & & \multicolumn{2}{|c|}{21 (unglycosylated) } & All MMPs. Binds to pro-MMP-2 \\
\hline & TIMP-3 & & \multicolumn{2}{|c|}{$\begin{array}{l}27 \text { (glycosylated) } \\
24 \text { (unglycosylated) }\end{array}$} & All MMPs. Binds to pro-MMP-2 and pro-MMP-9 \\
\hline & TIMP-4 & & \multicolumn{2}{|c|}{23 (unglycosylated) } & MMP-1, 2, 3, 7, 9. Binds to pro-MMP-2 \\
\hline
\end{tabular}

MMP = matrix metalloproteinase; TIMP = specific tissue inhibitor of MMP; TNF = tumor necrosis factor. 
positive correlation between macrophage number in the alveolar walls and the mildto-moderate emphysema status of patients with COPD (7). It is generally believed that the development of emphysema reflects a relative excess of cell-derived proteases that degrade the connective tissue of the lung and a relative paucity of anti-proteolytic defenses. This theory is often referred to as the "protease-antiprotease imbalance" hypothesis (Figure 1) and involves mainly serine proteases such as neutrophil elastase and MMPs.

There is increasing evidence for a role of MMPs in COPD (8). In patients with emphysema, there is an increase in BAL concentration and macrophage expression of MMP-1 (collagenase) and MMP-9 (gelatinase B) $(9,10)$. There is an increase in MMP9 activity in the lung parenchyma of patients with emphysema (11), and this is correlated with FEV1 (12). Alveolar macrophages from normal smokers express more MMP-9 than those from normal subjects (13), and there is an ever greater increase in cells in patients

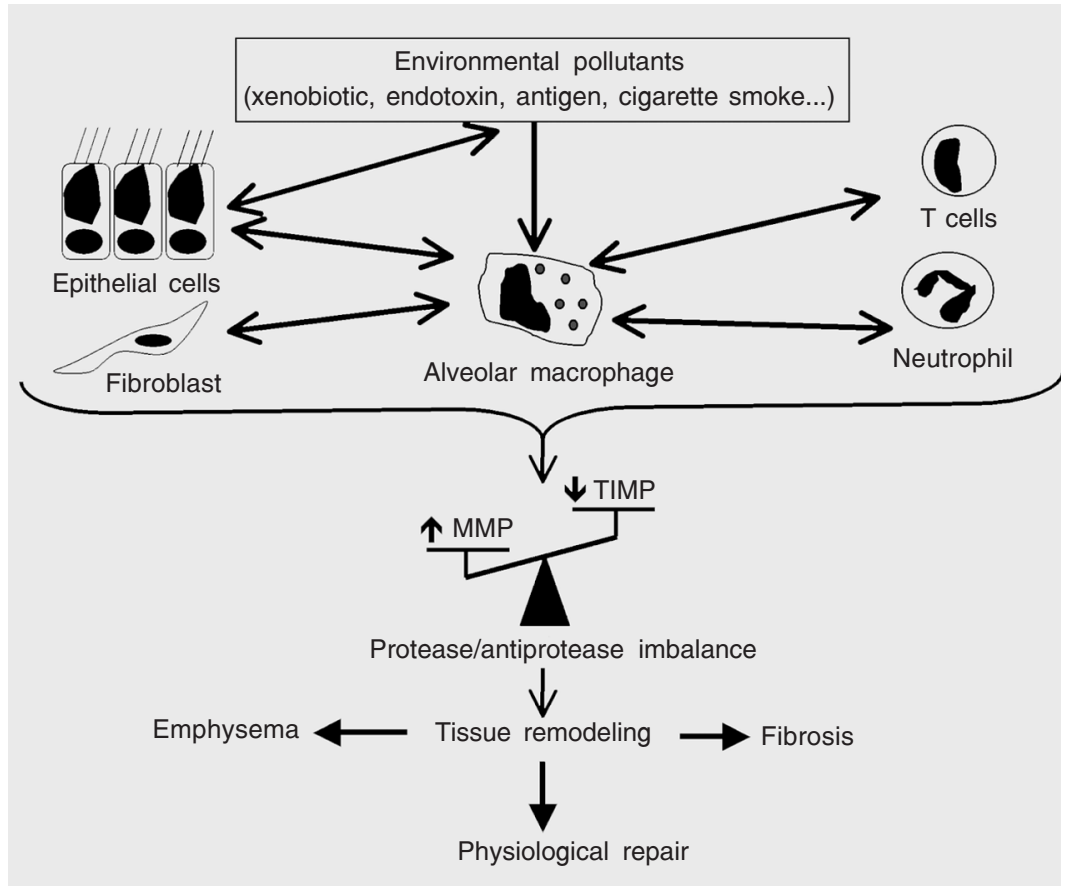

Figure 1. Role of inflammatory cells in the MMP/TIMP imbalance hypothesis and tissue remodeling. $\mathrm{MMP}=$ matrix metalloproteinase; $\mathrm{TIMP}=$ specific tissue inhibitor of MMPs. with COPD (14), which greatly enhances elastolytic activity (15). Indeed, it was shown that MMPs account for most of the elastolytic activity released by alveolar macrophages of COPD patients over prolonged periods of time (15). MMP-9 and the MMP-9/TIMP-1 ratio are increased in induced sputum of patients with COPD (16). MMP-8 and MMP9 do not only act as secreted enzymes, but are also bound to cells where they exert elastolytic activity.

MMP-12 is a $54-\mathrm{kDa}$ proenzyme that is processed into a $45-\mathrm{kDa}$ and then a $22-\mathrm{kDa}$ active form. The human gene, which is designated human macrophage metalloelastase, produces a $1.8-\mathrm{kb}$ transcript encoding a $470-$ amino acid protein that is $64 \%$ identical to the mouse protein. Both mRNA and the protein were detected in alveolar macrophages. As is the case for the mouse, the predicted human $54-\mathrm{kDa}$ protein is processed by loss of both $\mathrm{N}$ - and $\mathrm{C}$-terminal residues to a 22-kDa mature form (17).

MMP-12 seems to play a predominant role in the pathogenesis of chronic lung injury and particularly in emphysema. Indeed, MMP-12 is able to degrade different substrates, among them elastin (18). Elastin represents about $2.5 \%$ (weight/weight) of the dry weight of the lung and is distributed widely throughout the lungs (19). This protein is vital for the elastic recoil of the small airways and their ability to resist negative pressure collapse. In emphysema, the elastin content of the lung parenchyma is decreased and, ultrastructurally, elastic fibers are disorganized and probably nonfunctional (20). Moreover, elastin degradation products, such as desmosine, are increased in the urine of subjects with COPD (21) and correlate with the rate of lung function decline (22). In vitro studies on alveolar macrophages collected from COPD patients have shown their ability to degrade more elastin than macrophages collected from healthy volunteers (15). Using immunocytochemistry, we have observed MMP-12-positive macrophages in 
both COPD and control samples. However, the number of MMP-12-expressing macrophages and staining intensity were higher in BAL samples from COPD patients than in control subjects. Similar results were observed in bronchial biopsies with higher MMP-12 expression in COPD subjects and in controls. Enhanced MMP-12 activity was also detected in BAL fluids from patients with COPD in comparison with control subjects. The study in question demonstrated that COPD patients produce greater quantities of MMP-12 than controls, which may be a critical step in the pathogenesis of COPD and emphysema (23).

Studies using MMP-12 knock-out (KO) mice have demonstrated that macrophage recruitment in lungs and emphysema induced by long-term exposure to cigarette smoke were linked to MMP-12 (24). MMP$12 \mathrm{KO}$ mice were subjected to cigarette smoke over a 6-month period. In contrast to wild-type mice, MMP-12 KO mice did not have increased numbers of macrophages in their lungs and did not develop emphysema. A monthly intratracheal instillation of monocyte chemoattractant protein- 1 into the lungs of MMP-12 smoke-exposed KO mice caused an increase in macrophage recruitment. However, despite the presence of the macrophages, these MMP-12 KO mice did not develop air space enlargement in response to smoke exposure. These data suggest that MMP-12 is probably sufficient for the development of emphysema that results from chronic inhalation of cigarette smoke (24). More recently, Selman et al. (25) showed that the use of a synthetic MMP inhibitor reduced the inflammatory response and the emphysematous-derived lesions mainly at 2 months in a cigarette smoke-guinea pig model.

The macrophage recruitment observed in response to cigarette smoke could be linked to the elastolytic properties of MMP-12. Indeed, MMP-12 generates elastin-derived peptides and experiments performed in modi- fied Boyden chambers have shown that these elastin-derived peptides are chemotactic for monocytes (26). In a more recent study, it was reported that inflammatory lesions in the lungs of mice contained significantly more MMP-12 in macrophages at 10, 20, and 30 days of cigarette smoke exposure than in control mice exposed to 60 days (27). These results suggest that elastin degradation took place during the development of pulmonary change in mice exposed to cigarette smoke and activation of elastin-specific MMPs may be a determining factor for susceptibility to emphysema (27).

In an acute model of smoke exposure, neutrophils, desmosine and hydroxyproline, markers for elastin and collagen breakdown, respectively, were examined in BAL fluids from MMP-12 KO mice and wild-type mice $24 \mathrm{~h}$ after smoke exposure. None of these markers could be detected in MMP-12 KO mice, suggesting that acute smoke-induced connective tissue breakdown, the initial step towards emphysema, requires both neutrophils and MMP-12 and that the neutrophil influx is dependent on the presence of MMP12 (28). We recently demonstrated that MMP-12 KO mice have a reduced airway inflammatory reaction following exposure to two cigarettes twice a day for 2 days. Moreover, a phosphodiesterase type 4 (PDE4) inhibitor, cilomilast, was able to block the neutrophilia induced by cigarette smoke whereas corticosteroid treatment with dexamethasone was ineffective (29).

The direct effect of MMP-12 on the development of the inflammatory process in mouse airways has been evaluated using a recombinant form of human MMP-12 (rhMMP-12). A single instillation of rhMMP12 into the mouse airways elicited an intense inflammatory response characterized by the development of two successive phases. Indeed, rhMMP-12 induced an acute, severe and specific recruitment of neutrophils reaching a peak at $18 \mathrm{~h}$, while the number of macrophages remained stable throughout this 
period (30). The non-selective MMP inhibitor, marimastat, dexamethasone and the PDE4 inhibitor, rolipram, administered orally $1 \mathrm{~h}$ before rhMMP-12 instillation, were able to significantly decrease neutrophil recruitment at 4 and $24 \mathrm{~h}$. However, only marimastat was effective regarding macrophage recruitment at day 7. In BAL fluids, marimastat, dexamethasone and rolipram significantly decreased IL-6, KC (IL-8), macrophage inflammatory protein- $1 \alpha$, and MMP-9 levels. Recent results suggest that resident alveolar

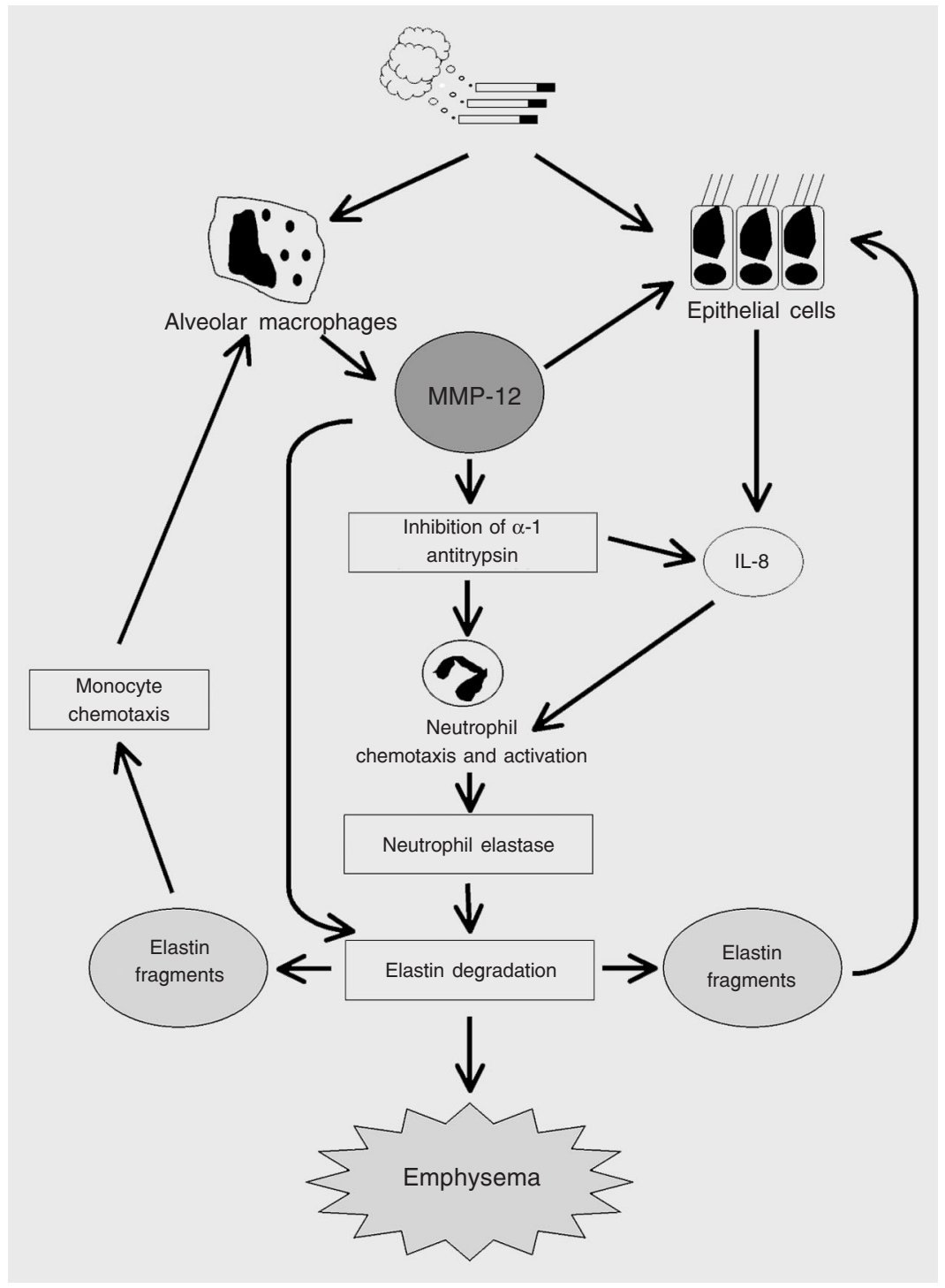

Figure 2. Role of inflammatory cells in the mechanism of action of macrophage metalloelastase (MMP-12). MMP = matrix metalloproteinase; IL-8 = interleukin 8. macrophages and recruited neutrophils do not play a role in the delayed macrophage recruitment induced by rhMMP-12 (Nénan $\mathrm{S}$, Bertrand $\mathrm{C}$ and Lagente $\mathrm{V}$, unpublished data). Because of its ability to induce an inflammatory response and tissue remodeling, it may be possible to consider MMP-12 as an essential component of the process leading to the development of the disease (Figure 2). Finally, the development of selective MMP inhibitors would provide some answers and may be useful for the determination of new therapeutic opportunities.

\section{Role of MMP in the development of pulmonary fibrosis}

Pulmonary fibrosis is a severe and crippling disease with a poor prognosis. Its main histological features include alveolar septal lesions, abnormal reepithelialization, fibroblast proliferation and excessive deposition of ECM macromolecules due to abnormal wound healing, and inflammation characterized by an influx of macrophages, neutrophils and lymphocytes. Idiopathic pulmonary fibrosis (IPF) - usual interstitial pneumonia - is the most frequent form of interstitial pneumonia of unknown etiology $(31,32)$.

It has been assumed that IPF is the consequence of chronic inflammation (33). Nevertheless, treatment with glucocorticoids, which are the most potent anti-inflammatory drugs, did not have the expected improving effects on the development of pulmonary fibrosis (34). Thus, the links between inflammation and fibrosis have been extensively debated and need to be clarified $(31,35)$. Transforming growth factor $\beta$ is a key fibrogenic mediator, promoting ECM synthesis by fibroblasts, and down-regulating collagen degradation through MMPs and TIMP (35-37).

MMPs are expressed at low levels in normal adult tissues, and their up-regulation appears to play an important role in the development of a number of pathological 
processes including pulmonary fibrosis. Further studies have demonstrated the involvement of MMPs in the pathogenesis of pulmonary fibrosis. BAL fluids from individuals with sarcoidosis (38) or pulmonary fibrosis (39) contain high levels of collagenase, thought to be neutrophil-derived, a fact that has been suggested to be related to the development of fibrosis in these subjects. However, analysis of lung tissue samples from subjects with hypersensitivity pneumonitis before and after treatment with prednisone indicated that, when the collagenase levels in the lung tissue were low, the subjects developed fibrosis. In those who improved or recovered, interstitial collagenase levels were two or three times higher than in those with fibrosis (40). It has been suggested that this is the result of repression of collagenase production by fibroblasts during fibrosis (40), although increased production of TIMP and reduced activation of the latent enzyme could also account for a low collagenase activity. Fukuda et al. (41) investigated MMP activity in the lungs of patients with bronchiolitis obliterans organizing pneumonia and IPF. In bronchiolitis obliterans organizing pneumonia, predominant MMPs, mainly active MMP-2, may constitute the mechanisms of reversibility of fibrotic changes in this disease. Conversely, a TIMP-2 increase in IPF may contribute to the stable ECM deposition and the irreversible pulmonary structural remodeling. Hayashi et al. (42) have suggested the involvement of MMP-2 in collagen deposition in IPF. Moreover, Pardo et al. (43) reported that cultured fibroblasts derived from patients with IPF exhibited an increased MMPs/collagenase ratio. The involvement of MMP-2 in ECM deposition was also suggested in a model of bleomycin-induced pulmonary fibrosis in rabbits (44). It has been recently suggested that in IPF there is a higher expression of TIMPs compared with collagenases, supporting the hypothesis that no degrading fibrillar collagen microenvironment is prevailing (31). Such observa- tions have been confirmed in vivo in a murine model of bleomycin-induced pulmonary fibrosis (45).

It has been reported that alveolar macrophages of patients with IPF are primed for MMP-9 expression and that MMP-9 activity secreted by macrophages tends to be normal in patients with IPF under glucocorticoid and immunosuppressive treatment (46). Although glucocorticoids appear to be efficient in inhibiting MMP activity, treatment with glucocorticoids did not appear to be correlated with clinical improvement of the patients. Lemjabbar et al. (46) concluded that MMP-9 may play a role in lung remodeling in IPF. However, the development of bleomycin-induced pulmonary fibrosis was not modified in MMP-9-deficient mice (47). Thus, this last study suggests that MMP-9 may not play an important role in the development of bleomycin-induced pulmonary fibrosis.

MMPs play a crucial role in the fibrogenic process, since it has been recently demonstrated that a selective MMP inhibitor, batimastat, markedly reduced bleomycininduced pulmonary fibrosis in mice (48). Gelatinase A (MMP-2) and gelatinase B (MMP-9) seem to be involved in pulmonary fibrosis, but their particular roles in the process remain unclear. Whereas MMP-9 is rather released by inflammatory cells and may be linked to inflammatory process-induced tissue remodeling, MMP-2 is synthesized by structural cells including fibroblasts, endothelial and epithelial cells, and may be associated with chronically impaired tissue remodeling leading to abnormal collagen deposition. Moreover, strong evidence implies that TIMP/MMP imbalance is an important element of the fibrogenic process: TIMP-1 and, to a lesser extent, TIMP-2 are induced in bleomycin-induced pulmonary fibrosis and several investigators have proposed some events promoting a "non-degrading microenvironment" with an exaggerated TIMP/MMP ratio in lung tissue that 
could lead to the fibrogenic process $(31,34$, 45). Besides, MMPs may be involved in the release and activation of profibrotic growth factors and cytokines and may therefore participate in the progression of pulmonary fibrosis (49).

The importance of early inflammatory components in the pathogenesis of pulmonary fibrosis has been extensively debated $(35,50)$. Thus, arguments in favor or against the role of acute and chronic inflammation have been reported on the basis of the data of numerous studies. It has been proposed that a "fibrogenic microenvironment" including some tissue remodeling mediators interacting with the ECM could suffice to launch the fibrogenic process. It seems that the early inflammatory response is critical for the development of bleomycin-induced fibrosis. This assumption is supported by the development of pulmonary fibrosis following repeated exposure of mice to an "inflammatory stimulus" such as lipopolysaccharide (51).

Several studies have reported that antioxidant treatment attenuates the bleomycininduced oxidative burden and subsequent pulmonary fibrosis (52-54). Moreover, the absence of extracellular superoxide dismutase exacerbates conditions that lead to inflammation and pulmonary fibrosis (55). Although these studies suggest that reactive oxygen species contribute to lung damage and fibrosis, they do not clearly indicate the mechanisms of the antioxidant effect. That is, antioxidant compounds may attenuate oxidative damage caused directly by bleomycin, or they may limit the impact of reactive oxygen species produced by phagocytes such as macrophages and neutrophils and thus interfere with the inflammatory process. We recently reported that mice deficient in the $\mathrm{p} 47^{\text {phox }}$ subunit of the NADPH oxidase complex do not develop pulmonary fibrosis after intranasal administration of bleomycin (56). This also suggests that an imbalance of the molar MMP-9/TIMP-1 ra- tio may influence the fibrogenic process in this model. Indeed, the MMP-9/TIMP-1 ratio did not change at day 1 after bleomycin administration in wild-type mice, but increased significantly in $\mathrm{KO}$ mice, leading to a "pro-fibrogenic environment" (56).

Over-expression of MMPs by lung fibroblasts has been blamed for much of the tissue destruction associated with airway inflammation. The potential involvement of MMPs in lung injury and remodeling raises the possibility of their regulation by therapeutic drugs and it was demonstrated that several MMPs appear to be down-regulated by steroids $(14,57,58)$. Because cyclic AMP is known to regulate fibroblast proliferation, as well as cytokine and ECM protein production, we evaluated the ability of selective phosphodiesterase type 4 inhibitors to inhibit ECM degradation (59). PDE4 inhibitors induced inhibition of TNF- $\alpha$-stimulated proMMP-2 release and prevented the increase in pro-MMP-1. These results underline a potential therapeutic benefit of selective PDE4 inhibitors in lung diseases associated with abnormal tissue remodeling.

\section{Concluding remarks}

Several studies have clearly shown that excessive levels of many MMPs are present in acute lung injury, COPD and pulmonary fibrosis associated with the inflammatory process. These results have led to the concept that modulation of airway remodeling including excessive proteolysis damage of the tissue may be of interest for future treatment. The excessive airway remodeling as a result of an imbalance in the equilibrium of the normal processes of synthesis and degradation of ECM components could be in favor of anti-proteases. Moreover, these observations emphasize that effective therapies for these disorders must be instituted early during the natural history of the disease, prior to the development of extensive lung destruction and fibrosis. 


\section{References}

1. Birkedal-Hansen H (1995). Proteolytic remodeling of extracellular matrix. Current Opinion in Cell Biology, 7: 728-735.

2. Murphy G \& Docherty A (1992). The matrix metalloproteinases and their inhibitors. American Journal of Respiratory Cell and Molecular Biology, 7: 120-125.

3. Pauwels R (2000). COPD: the scope of the problem in Europe. Chest, 117: 332S-335S.

4. Saetta M (1999). Airway inflammation in chronic obstructive pulmonary disease. American Journal of Respiratory and Critical Care Medicine, 160: S17-S20.

5. Eidelman D, Saetta MP, Ghezzo H et al. (1990). Cellularity of the alveolar walls in smokers and its relation to alveolar destruction. Functional implications. American Review of Respiratory Disease, 141: 1547-1552.

6. Finkelstein R, Fraser RS, Ghezzo H et al. (1995). Alveolar inflammation and its relation to emphysema in smokers. American Journal of Respiratory and Critical Care Medicine, 152: 1666-1672.

7. Tetley TD (2002). Macrophages and the pathogenesis of COPD. Chest, 121: 156S-159S.

8. Shapiro SD \& Senior RM (1999). Matrix metalloproteinases. Matrix degradation and more. American Journal of Respiratory Cell and Molecular Biology, 20: 1100-1102.

9. Finlay GA, O'Driscoll LR, Russell KJ et al. (1997). Matrix metalloproteinase expression and production by alveolar macrophages in emphysema. American Journal of Respiratory and Critical Care Medicine, 156: 240-247.

10. Betsuyaku T, Shipley JM, Liu Z et al. (1999). Neutrophil emigration in the lungs, peritoneum, and skin does not require gelatinase $B$. American Journal of Respiratory Cell and Molecular Biology, 20: 1303-1309.

11. Ohnishi K, Takagi M, Kurokawa $Y$ et al. (1998). Matrix metalloproteinase-mediated extracellular matrix protein degradation in human pulmonary emphysema. Laboratory Investigation, 78: 1077-1087.

12. Kang MJ, Oh YM, Lee JC et al. (2003). Lung matrix metalloproteinase-9 correlates with cigarette smoking and obstruction of airflow. Journal of Korean Medical Science, 18: 821-827.

13. Lim S, Roche N, Oliver BG et al. (2000). Balance of matrix metalloprotease- 9 and tissue inhibitor of metalloproteinase- 1 from alveolar macrophages in cigarette smokers. Regulation by interleukin-10. American Journal of Respiratory and Critical Care Medicine, 162: 1355-1360.

14. Russell RE, Culpitt SV, DeMatos C et al. (2002). Release and activity of matrix metalloproteinase-9 and tissue inhibitor of metalloproteinase- 1 by alveolar macrophages from patients with chronic obstructive pulmonary disease. American Journal of Respiratory Cell and Molecular Biology, 26: 602-609.

15. Russell RE, Thorley A, Culpitt SV et al. (2002). Alveolar macrophage-mediated elastolysis: roles of matrix metalloproteinases, cysteine, and serine proteases. American Journal of Physiology, 283: L867-L873.

16. Cataldo D, Munaut C, Noel A et al. (2000). MMP-2- and MMP-9linked gelatinolytic activity in the sputum from patients with asthma and chronic obstructive pulmonary disease. International Archives of Allergy and Immunology, 123: 259-267.

17. Shapiro SD, Kobayashi DK \& Ley TJ (1993). Cloning and characterization of a unique elastolytic metalloproteinase produced by human alveolar macrophages. Journal of Biological Chemistry, 268: 2382423829.

18. Gronski TJ, Martin RL, Kobayashi DK et al. (1997). Hydrolysis of a broad spectrum of extracellular matrix proteins by human macrophage elastase. Journal of Biological Chemistry, 272: 12189-12194.

19. Starcher BC (1986). Elastin and the lung. Thorax, 41: 577-585.

20. Shapiro SD (2000). Evolving concepts in the pathogenesis of chronic obstructive pulmonary disease. Clinics in Chest Medicine, 21: 621 . 632.

21. Stone PJ, Gottlieb DJ, O'Connor GT et al. (1995). Elastin and collagen degradation products in urine of smokers with and without chronic obstructive pulmonary disease. American Journal of Respiratory and Critical Care Medicine, 151: 952-959.

22. Gottlieb DJ, Stone PJ, Sparrow D et al. (1996). Urinary desmosine excretion in smokers with and without rapid decline of lung function: the Normative Aging Study. American Journal of Respiratory and Critical Care Medicine, 154: 1290-1295.

23. Molet S, Belleguic C, Léna $\mathrm{H}$ et al. (2004). Increase in macrophage elastase (MMP-12) in lungs from patients with chronic obstructive pulmonary disease. Inflammation Research, 54: 31-36.

24. Hautamaki RD, Kobayashi DK, Senior RM et al. (1997). Requirement for macrophage elastase for cigarette smoke-induced emphysema in mice. Science, 277: 2002-2004.

25. Selman M, Cisneros-Lira J, Gaxiola M et al. (2003). Matrix metalloproteinases inhibition attenuates tobacco smoke-induced emphysema in guinea pigs. Chest, 123: 1633-1641.

26. Senior RM, Griffin GL \& Mecham RP (1980). Chemotactic activity of elastin-derived peptides. Journal of Clinical Investigation, 66: 859862.

27. Valença SS, Da Hora K, Castro P et al. (2004). Emphysema and metalloelastase expression in mouse lung induced by cigarette smoke. Toxicologic Pathology, 32: 351-356.

28. Churg A, Zay K, Shay S et al. (2002). Acute cigarette smokeinduced connective tissue breakdown requires both neutrophils and macrophage metalloelastase in mice. American Journal of Respiratory Cell and Molecular Biology, 27: 368-374.

29. Leclerc O, Planquois JM, Lagente $V$ et al. (2004). A model of cigarette smoke-induced COPD inflammation in mice: steroid-insensitive but PDE4 sensitive. International Meeting on Nitric Oxide, Cytokines and Inflammation, Rio de Janeiro, RJ, Brasil, June 6-9 (Abstract).

30. Nenan S, Planquois JM, Berna P et al. (2005). Analysis of the inflammatory response induced by rhMMP-12 catalytic domain instilled in mouse airways. International Immunopharmacology, 5: 511-524.

31. Selman M, King TE \& Pardo A (2001). Idiopathic pulmonary fibrosis: prevailing and evolving hypotheses about its pathogenesis and implications for therapy. Annals of Internal Medicine, 134: 136-151.

32. Katzenstein AL \& Myers JL (1998). Idiopathic pulmonary fibrosis: clinical relevance of pathologic classification. American Journal of Respiratory and Critical Care Medicine, 157: 1301-1315.

33. Ward PA \& Hunninghake GW (1998). Lung inflammation and fibrosis. American Journal of Respiratory and Critical Care Medicine, 157: S123-S129.

34. Kolb M, Bonniaud P, Galt T et al. (2002). Differences in the fibrogenic response after transfer of active transforming growth factor-beta1 gene to lungs of "fibrosis-prone" and "fibrosis-resistant" mouse strains. American Journal of Respiratory Cell and Molecular Biology, 27: 141-150.

35. Gauldie J, Kolb M \& Sime PJ (2002). A new direction in the pathogenesis of idiopathic pulmonary fibrosis? Respiratory Research, 3: 1.

36. Santana A, Saxena B, Noble NA et al. (1995). Increased expression 
of transforming growth factor beta isoforms (beta 1, beta 2, beta 3 ) in bleomycin-induced pulmonary fibrosis. American Journal of Respiratory Cell and Molecular Biology, 13: 34-44.

37. Coker RK, Laurent GJ, Shahzeidi S et al. (1997). Transforming growth factors-beta 1, -beta 2, and -beta 3 stimulate fibroblast procollagen production in vitro but are differentially expressed during bleomycin-induced lung fibrosis. American Journal of Pathology, 150: $981-991$

38. O'Connor C, Odlum C, Van Breda A et al. (1998). Collagenase and fibronectin in bronchoalveolar lavage fluid in patients with sarcoidosis. Thorax, 43: 393-400.

39. Gadeck JE, Kelman JA, Fens GA et al. (1979). Collagenase in the lower respiratory tract of patients with idiopathic pulmonary fibrosis. New England Journal of Medicine, 301: 737-742.

40. Selman M \& Pardo A (1991). Potential role of proteases in pulmonary fibrosis. Annals of the New York Academy of Sciences, 624: 297-306.

41. Fukuda $Y$, Ishizaki M, Kudoh S et al. (1998). Localisation of matrix metalloproteinases-I, -2, and -9 and tissue inhibitor of metalloproteinase-2 in interstitial lung diseases. Laboratory Investigation, 78: 687-698.

42. Hayashi T, Stetler-Stevenson WG, Fleming MY et al. (1996). Immunohistochemical study of metalloproteinases and their tissue inhibitors in the lungs of patients with diffuse alveolar damage and idiopathic pulmonary fibrosis. American Journal of Pathology, 149: 1241-1256.

43. Pardo A, Selman M, Ramirez R et al. (1992). Production of collagenase and tissue inhibitor of metalloproteinases by fibroblasts derived from normal and fibrotic human lung. Chest, 102: 1085-1089.

44. Yaguchi T, Fukuda Y, Ishizaki M et al. (1998). Immunohistochemical and gelatin zymography studies for matrix metalloproteinases in bleomycin-induced pulmonary fibrosis. Pathology International, 48: 954-963.

45. Madtes DK, Elston AL, Kaback LA et al. (2001). Selective induction of tissue inhibitor of metalloproteinase-1 in bleomycin-induced pulmonary fibrosis. American Journal of Respiratory Cell and Molecular Biology, 24: 599-607.

46. Lemjabbar H, Gosset P, Lechapt-Zalcman E et al. (1999). Overexpression of alveolar macrophage gelatinase B (MMP-9) in patients with idiopathic pulmonary fibrosis: effects of steroid and immunosuppressive treatment. American Journal of Respiratory Cell and Molecular Biology, 20: 903-913.

47. Betsuyaku T, Fukuda Y, Parks WC et al. (2000). Gelatinase B is required for alveolar bronchiolization after intratracheal bleomycin. American Journal of Pathology, 157: 525-535.
48. Corbel M, Caulet-Maugendre S, Germain N et al. (2001). Inhibition of bleomycin-induced pulmonary fibrosis in mice by the matrix metalloproteinase inhibitor batimastat. Journal of Pathology, 193: 538545.

49. Winkler MK \& Fowlkes JL (2002). Metalloproteinase and growth factor interactions: do they play a role in pulmonary fibrosis? American Journal of Physiology, 283: L-1-L-11.

50. Strieter RM (2002) Con: Inflammatory mechanisms are not a minor component of the pathogenesis of idiopathic pulmonary fibrosis. American Journal of Respiratory and Critical Care Medicine, 165: 1206-1207 (Discussion 1207-1208).

51. Corbel M, Théret N, Caulet-Maugendre S et al. (2001). Metalloproteinase activity is associated with inflammation and fibrosis following chronic lung injury in mice. Inflammation Research, 50: 129-135.

52. Serrano-Mollar A, Closa D, Prats $\mathrm{N}$ et al. (2003). In vivo antioxidant treatment protects against bleomycin-induced lung damage in rats. British Journal of Pharmacology, 138: 1037-1048.

53. Wang HD, Yamaya M, Okinaga S et al. (2002). Bilirubin ameliorates bleomycin-induced pulmonary fibrosis in rats. American Journal of Respiratory and Critical Care Medicine, 165: 406-411.

54. Punithavathi D, Venkatesan N \& Babu M (2000). Curcumin inhibition of bleomycin-induced pulmonary fibrosis in rats. British Journal of Pharmacology, 131: 169-172.

55. Fattman CL, Chang LY, Termin TA et al. (2003). Enhanced bleomycin-induced pulmonary damage in mice lacking extracellular superoxide dismutase. Free Radical Biology and Medicine, 35: 763771.

56. Manoury B, Nénan S, Leclerc O et al. (2005). The absence of reactive oxygen species production protects mice against bleomycin-induced pulmonary fibrosis. Respiratory Research, 6: 11.

57. Carver JE, Galloway WA \& Robinson C (1999). Inhibition of gelatinase activity in human airway epithelial cells and fibroblasts by dexamethasone and beclomethasone. British Journal of Pharmacology, 127: 1119-1128.

58. Corbel M, Lagente V, Théret $\mathrm{N}$ et al. (1999). Comparative effects of betamethasone, cyclosporin and nedocromil sodium in acute pulmonary inflammation and metalloproteinase activities in bronchoalveolar lavage fluid from mice exposed to lipopolysaccharide. Pulmonary Pharmacology and Therapeutics, 12: 165-171.

59. Martin-Chouly CAE, Astier A, Jacob C et al. (2004). The selective phosphodiesterase 4 inhibitor $\mathrm{Cl}-1044$ inhibits TNF- $\alpha$ induced release of gelatinase A from human lung fibroblasts. Life Sciences, 75: 823-840. 